\section{AL-AZHAR Dental Journal}

F o r
G $\quad$ i $\quad r \quad l$
The Official Publication of The Faculty of Dental Medicine For Girls, Al-Azhar University Cairo, Egypt.

Print ISSN 2537-0308 • Online ISSN 2537-0316

ADJ-for Girls, Vol. 7, No. 4, October (2020) - PP. 621:625

\title{
Assessment of Orthodontic Treatment Outcomes in Maxillary Protrusion Enhanced by Guided Piezoelectric Corticotomy with Bone Graft (Comparative study)
}

\author{
Shereen A. El Mahlawy ${ }^{1 *}$, Samir A. Ibrahim ${ }^{2}$, Ahmed E. Salama ${ }^{3}$, Naglaa S. El-Kilani ${ }^{4}$, Ghada A. Khalifa ${ }^{5}$
}

Codex : 77/20.10

azhardentj@azhar.edu.eg

http://adjg.journals.ekb.eg

DOI: $10.21608 / \operatorname{adjg} .2020 .12823 .1143$

Pediatric Dentistry \& Orthodontics ( Pediatric Dentistry, Orthodontics)

\section{KEYWORDS}

Periodontally accelerated, osteogenic orthodontics,

Piezocision.

\begin{abstract}
Purpose: This study aimed to compare orthodontic treatment outcomes in maxillary protrusion enhanced by piezoelectric Corticotomy with and without bone graft guided by 3D surgical template. Subjects and Methods: sample of 20 patients with age range (18-25) year-old allocated randomly into 2 groups, Group I: patients were treated with piezocision corticotomy without bone graft guided by surgical template. Group II: patients were treated with piezocision corticotomy with bone graft guided by surgical template. Treatment changes were evaluated for each group and compared between groups. Data were analyzed using Paired t-test for each group and Student t-test to compare between the two groups. Results: There was a significant decrease in mean SNA, ANB, H angles, SN-U1, MP-L1, overjet measurements and significant increase in mean interincisal and nasolabial angles for both groups. While there was a non-significant difference between mean differences in skeletal, dental and soft tissue measurements between the two groups $(\mathrm{p}<0.05)$. Both groups revealed decrease in the mean en masse retraction time. Conclusion: Maxillary protrusion cases treated with piezoelectric corticotomy revealed improvements in profile, esthetics and acceleration in orthodontic tooth movement.
\end{abstract}

- Paper extracted from Doctor thesis titled “Assessment of Orthodontic Treatment Outcomes in Maxillary Protrusion Enhanced by Guided Piezoelectric Corticotomy with Bone Graft"

1. Assistant Lecturer at Orthodontic Department, Faculty of Oral and Dental Medicine, Fayom University, Egypt

2. Professor of Orthodontics, Faculty of Dental Medicine for Girls, Al-Azhar University, Cairo, Egypt

3. Professor and Head of Orthodontic Department, Faculty of Dental Medicine for Girls, Al-Azhar University, Cairo, Egypt

4. Professor and Head of Oral Medicine, Periodontology, Diagnosis and Radiology Department, Faculty of Dental Medicine for Girls, Al-Azhar University, Cairo, Egypt

5. Professor of Oral and Maxillofacial Surgery, Faculty of Dental Medicine for Girls, Al-Azhar University, Cairo, Egypt

* Corresponding author email: dentistshreen.a@gmail.com 


\section{INTRODUCTION}

The innovation of Corticotomy facilitated orthodontics provides solutions to obstacles in the adults' orthodontic therapy ${ }^{(1)}$.

Corticotomy assisted orthodontics was invented by Kole ${ }^{(2)}$ who proposed bony block movement by osteotomy in the alveolar process.

Facilitated orthodontic tooth movement is due to Regional Acceleratory Phenomenon (RAP) and not on the block movement of bone ${ }^{(3)}$. In healthy tissues RAP decrease the bone density whereas the bone matrix volume remains constant. The application of orthodontic force alone is sufficient to stimulate mild RAP activity. When tooth movement is accompanied with selective decortication, RAP is maximized ${ }^{(4)}$.

Periodontally Accelerated Osteogenic Orthodontics (PAOO) technique based on RAP. Osteopenia due to surgical trauma will reduce the resistance of bone and accelerate tooth movement ${ }^{(5)}$.

The advantages of PAOO include less treatment time, the teeth can be accelerated two to three times in third to fourth the time needed for conventional orthodontic treatment, induce expansion, differential tooth movement, facilitate traction of teeth impacted and increase stability post orthodontic therapy. With PAOO the preexisting alveolar volume becomes not a problem, reduce occurrence of fenestrations and dehiscence ${ }^{(6)}$.

Piezoelectric surgery (PES) is a new technique introduced in bone surgery for corticotomies by utilizing a surgical device called the Mectron PES. In comparison to conventional bone cutting instruments, PES is safe in bone surgery and provides precision ${ }^{(7)}$

The following study was done to assess the treatment outcomes of flapless piezoelectric corticotomy procedure accompanied with bone grafting.

\section{MATERIAL AND METHODS}

A statistical power analysis was done to determine the sample size. The alpha level was $(0.05)$ $5 \%$, power of $80 \%$ and the suggested sample size was 20 patients for both groups (10 each group). The study was performed on patients selected from the clinic of Orthodontic Department, Faculty of Dental Medicine for Girls, Al-Azhar University. Consents were obtained from the patients after explanation of the aim and method of the study.

Twenty adult female patients were selected with maxillary protrusion and orthodontic treatment entailing the extraction of maxillary first premolar teeth. Randomly the sample was allocated into 2 groups: Group I: Consist of 10 patients that were treated with piezocision corticotomy without bone graft guided by surgical template. Group II: Consist of 10 patients that were treated with piezocision corticotomy with bone graft guided by surgical template.

Cephalometric records pre, post treatment and cone beam computed tomography of upper arch pre, 6 months post-surgery were done. Fixed direct bond Roth system appliance with (0.022"x0.028") inch slot was performed. Double Transpalatal bar appliance was soldered to the maxillary 1 st and $2 \mathrm{nd} \mathrm{mo-}$ lar bands. Leveling and alignment arch wires were placed in sequential order.

The Piezocision corticotomy was done using Ultrasonic Piezotome guided with 3D surgical template in both groups. In Group II a tunnel was performed by micro periosteal elevator inserted between the gingival incisions, allowed wide subperiosteal tunnelled dissection, to provide enough space for bone grafting (xenograft) and PRF. Fig (1)

Maxillary six anterior teeth EN masse retraction along (0.016x 0.022) inch stainless steel arch wire using sliding mechanics was initiated immediately after the surgical procedure. Extraction Space closure was applied postsurgical by elastomeric memory closed Power chains extended from the hook of maxillary canine bracket to the hook of 


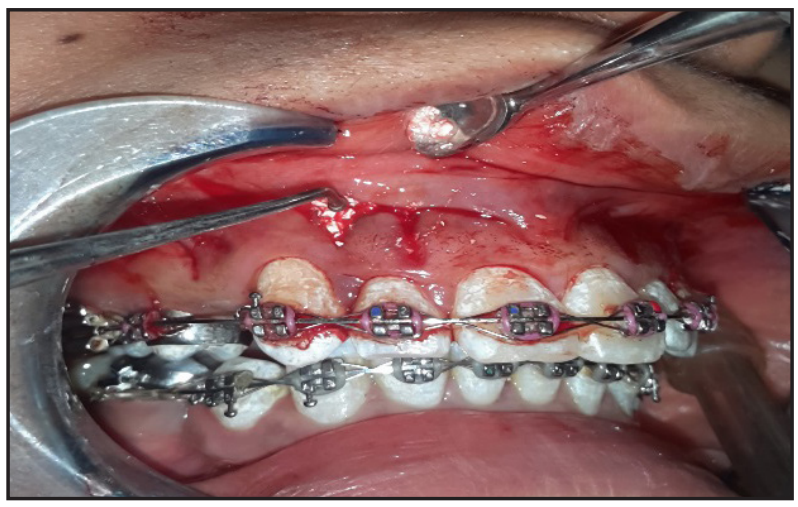

Figure (1) Inserting bone graft in a tunnel

maxillary first molar band with retraction force of approximately (250-300 gm). Orthodontic adjustments were performed every 2 weeks until extraction space closure.

Total retraction time was estimated from beginning of retraction till complete space closure.
Cephalometric analysis was used for evaluation of soft and hard tissue changes before and post treatment in both groups.

\section{RESULTS}

The results of the current study were collected, tabulated and statistically analyzed using SPSS. Paired t-test used to study changes post treatment for each group and Student test to evaluate comparison between the 2 groups.

\section{Cephalometric measurements:}

There was a significant decrease after treatment at both groups in mean SNA, ANB, SN-U1, MP-L1, overjet, $\mathrm{H}$ angle and significant increase in mean interincisal, nasolabial angle while there was a nonsignificant difference between mean changes in all measurements between the two groups. Table (1)

Table (1) Mean, SD values of cephalometric measurements post-treatment between the two groups

\begin{tabular}{|c|c|c|c|c|c|c|c|}
\hline \multirow{2}{*}{ Type of measurements } & \multirow{2}{*}{ Measurement } & \multicolumn{2}{|c|}{ Group I } & \multicolumn{2}{|c|}{ Group II } & \multirow{2}{*}{$\begin{array}{c}\text { Mean } \\
\text { Difference }\end{array}$} & \multirow{2}{*}{ P value } \\
\hline & & Mean & SD & Mean & SD & & \\
\hline \multirow{5}{*}{$\begin{array}{c}\text { Skeletal } \\
\text { Measuements }\end{array}$} & SNA & 80.67 & 1.03 & 80.50 & 1.05 & 0.17 & 0.7872 \\
\hline & SNB & 76.67 & 0.82 & 77.00 & 2.28 & -0.33 & 0.7471 \\
\hline & ANB & 4.00 & 1.26 & 4.00 & 0.63 & 0.00 & 1.0000 \\
\hline & FACIAL Ấ & 84.00 & 3.22 & 83.67 & 2.34 & 0.33 & 0.8421 \\
\hline & Ấ of Convexity & 8.50 & 3.39 & 9.33 & 3.78 & -0.83 & 0.6961 \\
\hline \multirow{5}{*}{$\begin{array}{c}\text { Dental } \\
\text { Measurements }\end{array}$} & 1_to $\mathrm{SN}$ & 99.33 & 3.33 & 101.33 & 3.88 & -2.00 & 0.3610 \\
\hline & $1^{-}$to M.P & 96.50 & 6.16 & 98.83 & 1.60 & -2.33 & 0.4054 \\
\hline & 1_to $1^{-}$ & 126.50 & 5.89 & 125.17 & 4.79 & 1.33 & 0.6766 \\
\hline & Over jet & 3.17 & 0.75 & 2.83 & 0.75 & 0.33 & 0.4608 \\
\hline & Over bite & 3.33 & 0.52 & 2.83 & 0.75 & 0.50 & 0.2131 \\
\hline \multirow{3}{*}{$\begin{array}{c}\text { Soft tissue } \\
\text { Measurements }\end{array}$} & Nasolabial & 102.50 & 4.97 & 103.50 & 5.58 & -1.00 & 0.7498 \\
\hline & $\mathbf{H}^{\wedge}$ & 19.00 & 3.03 & 20.67 & 3.72 & -1.67 & 0.4160 \\
\hline & $\mathbf{Z}^{\wedge}$ & 64.33 & 8.98 & 63.00 & 6.20 & 1.33 & 0.7716 \\
\hline
\end{tabular}

$S D=$ Standard Deviation, *: Significant at $P \leq 0.05$ 


\section{Retraction time:}

Both groups (piezoelectric corticotomy without bone graft group) and (piezoelectric corticotomy with bone graft group) revealed decrease in the mean en masse retraction time (127.5 \pm 17.01$)$ and $(129.5 \pm 11.78)$ days respectively while there was a non-significant change in mean difference of retraction time between the two groups. Table (2)

Table (2) Mean, SD and Mean difference of Retraction time between the two groups

\begin{tabular}{|c|c|c|c|c|c|c|}
\hline \multirow{2}{*}{$\begin{array}{c}\text { Rate of } \\
\text { retraction } \\
\text { (days) }\end{array}$} & \multicolumn{2}{|c|}{ Group I } & \multicolumn{2}{c|}{ Group II } & \multirow{2}{*}{$\begin{array}{c}\text { Mean } \\
\text { Difference }\end{array}$} & $\begin{array}{c}\text { P } \\
\text { value }\end{array}$ \\
\cline { 2 - 7 } & 127.00 & 17.01 & 129.50 & 11.78 & -2.50 & 0.7740 \\
\hline
\end{tabular}

$S D=$ Standard Deviation, *: Significant at $P \leq 0.05$

\section{DISCUSSION}

Piezosurgery is a non-invasive procedure without flap which combine incisions of cortex with selective tunneling that permits for bone or soft-tissue graft.

Time is an important factor in orthodontic treatment. The mean en masse retraction time of the current study was in accordance with previous studies $^{(4,7)}$. These results also agreed with those of study which reported the mean time for the en masse retraction in the corticotomy group was observed to be $(131 \pm 7.5$ days $)$ in contrast to $(234 \pm 9$ days $)$ for the conventional technique ${ }^{(8)}$.

The results confirmed by previous study which suggested that the high rate of tooth movement with corticotomy to a RAP, in which bone turnover increased and mineral content decreased ${ }^{(9)}$.

In the present study both groups who undergone flapless piezoelectric corticotomy showed a significant decrease in mean SNA angle post treatment which revealed the change of anteroposterior relation of maxilla to cranial base and also showed a significant decrease in ANB angle while the whole change was brought by the maxilla that provides change in profile and esthetics.
These results agreed with a study that found a significant decrease in SNA, ANB angle measurements with corticotomy group than conventional orthodontics $^{(10)}$.

In the present study both groups who undergone flapless piezoelectric corticotomy showed a significant decrease in mean SN-U1, MP-L1 measurements post treatment and significant increase in mean interincisal angle, owing to the corticotomy procedure actively reducing the proclination of the upper incisors in relation to the mandibular incisors.

These results are in agreement with another clinical study for evaluation of corticotomy facilitated orthodontics in maxillary anterior segment retraction in which the dental parameters revealed that the inclination of upper incisor significantly reduced, the interincisal angle was also increased to give the inference that there was a significant change of the angle $^{(11)}$.

In the current study, there was a significant decrease in mean overjet measurements post treatment in both groups which improved lip competence.

Results were in agreement with a study for comparing of cephalometric evaluations in anterior segment retraction combined with alveolar corticotomies before and after treatment, which showed that 
the overjet was significantly improved, excessive overjet was effectively treated with approximately $5 \mathrm{~mm}$ decrease ${ }^{(12)}$.

In the present study, there was a significant increase in mean Nasolabial angle measurements and significant decrease in mean $\mathrm{H}$ angle measurements such that upper lips showed retrusion with the backward movement of A point and retraction of proclined maxillary incisors which revealed improvement in soft tissue profile and lip competence.

The soft tissue changes of the current study were in agreement with a study evaluating the efficacy of corticotomy facilitated treatment in skeletal class II patients which found increase in nasolabial angle in corticotomy group than control group ${ }^{(13)}$.

\section{CONCLUSION}

From the current study, the following conclusion could be extracted:

1. Piezoelectric surgery provide high precision and safe surgery in bone.

2. Corticotomy facilitated orthodontics not only accelerate orthodontic tooth movement but also improve profile in maxillary protruded patients regardless of bone grafting.

\section{REFERENCES}

1. Amit G, JPS K, Pankaj B. periodontally accelerated osteogenic orthodontics (PAOO) - a review. J Clin Exp Dent. 2012; 4:292-6.

2. Kole H. Surgical operation on the alveolar ridge to correct occlusal abnormalities. Oral Surg Oral Med Oral Pathol. 1959; 12:515-29.

3. Frost HM. The regional acceleratory phenomenon: a review. Henry Ford Hosp Med J. 1983; 31:3-9.
4. Wilcko MT, Wicklo WM, Bissada NF. An Evidencebased Analysis of Periodontally Accelerated Orthodontic and Osteogenic Techniques: a Synthesis of Scientific Perspectives: Semin Orthod.2008; 14: 305-16.

5. Wilcko WM, Wilcko T, Bouquot JE, Ferguson DJ. Rapid orthodontics with alveolar reshaping: Two case reports of decrowding. Int J Period Rest Dent 2001; 21:9-19.

6. Vercelloti T. Technological characteristics and clinical indications of piezoelectric bone surgery. Minerva Stomatol 2004; 53:207-14.

7. Murphy KG, Wilcko TM, Wilcko MW, Ferguson DJ. Periodontal Accelerated Osteogenic Orthodontics: A Description of the Surgical Technique. J Oral Maxillofac Surg. 2009; 67: 2160-66.

8. Bhattacharya P, Bhattacharya H, Anjjum A, Bhandari R, Agarwal DK, Gupta A, et al. Assessment of corticotomy facilitated tooth movement and changes in alveolar bone thickness -a CT scan study.J.clinc.Diagn.Res.2014; 8:26-30.

9. Wilcko MT, Wilcko WM, Pulver JJ, BissadaNF, Bouquet JE. Accelerated osteogenic orthodontics technique: Stage surgically facilitated rapid orthodontic technique with alveolar augmentation. J Oral Maxillofac Surg. 2009; 67:2149-59.

10. El Kilani N S, Ibrahim S A, Abd Meneim M H. Cone Beam Guided Corticotomy Using Piezoelectric Surgery. J. Int Academy of Period 2016; 18: 76-85.

11. Reddy CM, Umashankar K, Reddy DS. A Clinical Assessment of Corticotomy Facilitated Orthodontics in the Retraction of Maxillary Anterior Segment. J Ind Orthod Soc 2014; 48(4):291-300.

12. Ibrahim G. Comparison of the Amount of Anchorage Loss of the Molars with and without the Use of Implant Anchorage during Anterior Segment Retraction Combined with Alveolar Corticotomies. J Dent Health Oral Disord Ther 2015; 2: 00067.

13. Cheng L, Zhao CY, Li M, pan CQ, Yan B, Wang L. Evaluation on efficacy of corticotomy facilitated treatment in skeletal class II. Chin J Orthod .2017; 52:404-09. 